Article

\title{
In situ generated acylimidazolium acetate as an efficient catalyst and acylating agent for the acetylation of alcohols, phenols, and amines at ambient temperature
}

\author{
Najmeh Nowrouzi *, Seyedeh Zahra Alizadeh \\ Department of Chemistry, Faculty of Sciences, Persian Gulf University, Bushehr 75169, Iran
}

\section{A R T I C L E I N F 0}

\section{Article history:}

Received 6 May 2013

Accepted 7 July 2013

Published 20 September 2013

Keywords:

Acetylation

Acylimidazolium acetate

Imidazole

Ionic liquid

\section{A B S T R A C T}

Acylimidazolium acetate was readily prepared in situ from the reaction of imidazole with acetic anhydride and subsequently acted as a catalyst and acylating agent for the efficient acetylation of alcohols, phenols, and amines at ambient temperature.

(C) 2013, Dalian Institute of Chemical Physics, Chinese Academy of Sciences. Published by Elsevier B.V. All rights reserved.

\section{Introduction}

Functional group protection strategies are essential to the design and implementation of effective organic syntheses and are used extensively in the preparation of multifunctional organic compounds [1,2]. Of the many different protecting methodologies available, the acetylation of alcohols, phenols, and amines with acetic anhydride in the presence of protic acids [3], Lewis acid catalysts [4-14], or basic reagents [15-20] is particularly important and one of the preferred approaches for the protection of these functional groups because of the ease with which these transformations can be affected, as well as the stability of the resulting acetates under mild acidic and basic conditions. Furthermore, acetates can be readily deprotected as necessary to afford the parent functionality. Although acylation reactions are traditionally conducted in the presence of a stoichiometric quantity of a base, such as pyridine, 4-( $N, N$-dimethylamino)pyridine (DMAP), triethylamine or tributylphosphine, which are very toxic in nature and difficult to remove from the product, as well as being flammable and possessing an unpleasant odor, a variety of homogeneous and heterogeneous acidic catalysts [3-14] such as simple metal salts, metal triflates, and solid acid catalysts have also been reported to be effective for acetylation reactions involving acetic anhydride. Although these procedures provide an improvement over the traditional methodologies, many of these methods require long reaction times, forcing reaction conditions, tedious workup procedures, moisture sensitive or expensive catalysts, extensive catalyst preparation processes, and the use of halogenated volatile organic solvents, and generally provide poor yields of the desired products. The development of a mild, non-toxic, and efficient catalyst for the acetylation of alcohols, phenols, and amines is therefore highly desirable.

\section{Experimental}

All of the chemicals used in the current study were purchased from Fluka, Merck, and Aldrich chemical companies. 
The acetylated products were characterized by the comparison of their spectral (IR and ${ }^{1} \mathrm{H}$ and ${ }^{13} \mathrm{C}$ NMR) and physical data with those of the authentic samples.

In a typical procedure for the conversion of aniline into acetanilide, aniline $(1.0 \mathrm{mmol}, 0.09 \mathrm{~mL})$ was added to a stirred mixture of acetic anhydride (2.0 mmol, $0.188 \mathrm{~mL}$ ) and imidazole $(0.08 \mathrm{mmol}, 0.005 \mathrm{~g}$ ) at room temperature, and the progress of the reaction was monitored by TLC. Upon completion of the reaction ( $1 \mathrm{~min})$, water $(3 \mathrm{~mL}$ ) was added to the mixture, resulting in the precipitation of the acetanilide, which was collected by filtration and washed with water before being dried under vacuum at $70{ }^{\circ} \mathrm{C}$ to give the desired product in high purity as colorless crystals $\left(0.128 \mathrm{~g}, 95 \%\right.$ yield). ${ }^{1} \mathrm{H}$ NMR (400 $\mathrm{MHz}_{\mathrm{CDCl}}$ ): $\delta 2.17(\mathrm{~s}, 3 \mathrm{H}), 7.12(\mathrm{t}, J=7.2 \mathrm{~Hz}, 1 \mathrm{H}), 7.31(\mathrm{t}, J=$ $7.6 \mathrm{~Hz}, 2 \mathrm{H}), 7.54$ (d, $J=7.6 \mathrm{~Hz}, 2 \mathrm{H}), 8.21$ (s, $1 \mathrm{H}) .{ }^{13} \mathrm{C}$ NMR (100 $\mathrm{MHz}_{\mathrm{CDCl}}$ ): $\delta 24.4,120.2,124.3,128.9,138.1,169.2$.

In a typical procedure for the conversion of a benzyl alcohol into a benzyl acetate, benzyl alcohol $(1.0 \mathrm{mmol}, 0.1 \mathrm{~mL})$ was added to a stirred solution of imidazole $(0.08 \mathrm{mmol}, 0.005 \mathrm{~g})$ and acetic anhydride ( $2.0 \mathrm{mmol}, 0.188 \mathrm{~mL})$ at ambient temperature, and the progress of the reaction was monitored by TLC. Upon completion of the reaction $(3 \mathrm{~h})$, the residue was subjected to purification on a short column of silica gel, using $n$-hexane/ethyl acetate (10:1) as the eluent, to give the desired benzyl acetate as colorless liquid $\left(0.14 \mathrm{~g}, 94 \%\right.$ yield). ${ }^{1} \mathrm{H}$ NMR $\left(400 \mathrm{MHz}, \mathrm{CDCl}_{3}\right): \delta 2.13(\mathrm{~s}, 3 \mathrm{H}), 5.14(\mathrm{~s}, 2 \mathrm{H}), 7.29-7.43(\mathrm{~m}$, $5 \mathrm{H})$.

In a typical procedure for the conversion of 4-ethylphenol into 4-ethylphenyl acetate, 4-ethylphenol (1 mmol, $0.122 \mathrm{~g}$ ) was added to a stirred solution of imidazole ( $0.08 \mathrm{mmol}, 0.005$ g) and acetic anhydride ( $2.0 \mathrm{mmol}, 0.188 \mathrm{~mL})$ at ambient temperature, and the progress of the resulting reaction was monitored by TLC. Upon completion of the reaction $(2.5 \mathrm{~h})$, the crude product mixture was purified by column chromatography on silica gel using $n$-hexane/ethyl acetatre (10:1) as the eluent to give 4-ethylphenyl acetate as colorless liquid $(0.143 \mathrm{~g}$, $87 \%$ yield). ${ }^{1} \mathrm{H}$ NMR (400 MHz, $\left.\mathrm{CDCl}_{3}\right): \delta 1.31(\mathrm{t}, J=7.6 \mathrm{~Hz}, 3 \mathrm{H})$, $2.33(\mathrm{~s}, 3 \mathrm{H}), 2.71(\mathrm{q}, J=7.6 \mathrm{~Hz}, 2 \mathrm{H}), 7.07$ (d, $J=8.4 \mathrm{~Hz}, 2 \mathrm{H}), 7.27$ $(\mathrm{d}, J=8.4 \mathrm{~Hz}, 2 \mathrm{H}) .{ }^{13} \mathrm{C}$ NMR $\left(100 \mathrm{MHz}, \mathrm{CDCl}_{3}\right): \delta 15.6,21.1,28.3$, 121.3, 128.8, 141.7, 148.7, 169.7 .

In a typical procedure for the reusability of the catalyst, $\mathrm{N}$-acylimidazolium acetate is soluble in water. At the end of each reaction, $n$-hexane $(5 \mathrm{~mL})$ and water $(5 \mathrm{~mL})$ were added to the reaction mixture, and the resulting mixture was stirred for $3 \mathrm{~min}$. The organic layer was then collected and evaporated to dryness to give a crude residue, which was purified by column chromatography over silica gel to give the pure product, as described above. The aqueous phase containing the ionic liquid (IL) was evaporated to dryness under reduced pressure to give the catalyst, which was subsequently recovered and reused.

\section{Results and discussion}

With regard to addressing some of the problems associated with chemical pollution, ILs have been the subject of increasing levels of attention as environmentally friendly reaction media

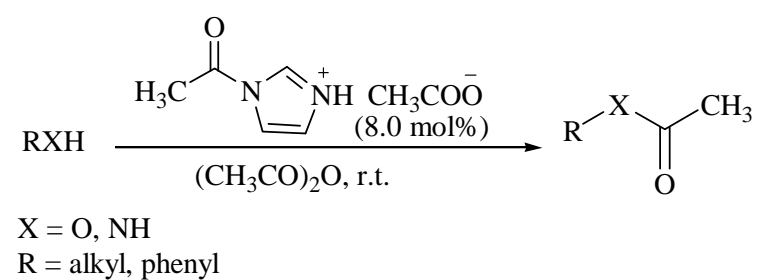

Scheme 1. Acylimidazolium acetate catalyzed acetylation of alcohols, phenols, and amines with acetic anhydride.

and/or catalysts for organic synthesis. For these reasons, a variety of different reactions [21-24], including the acetylation of hydroxyl groups, have been conducted in ILs. Herein, we report that the in situ generated IL acylimidazolium acetate can be used an excellent acylating agent and catalyst for the acetylation of alcohols, phenols, and amines (Scheme 1).

To begin with, we conducted a series of preliminary experiments using benzyl alcohol as a model compound, which was reacted with acetic anhydride and imidazole at ambient temperature. Under these conditions, $8.0 \mathrm{~mol} \%$ of acylimidazolium acetate was found to be sufficient for the complete conversion of $1.0 \mathrm{mmol}$ of alcohol in the presence of $2.0 \mathrm{mmol}$ of acetic anhydride. Further increases in the amount of the catalyst led to a reduction in the reaction time with only negligible increases in the yield. To explore the generality and scope of this new method, a verity of different alcohols were acetylated under the optimized reaction conditions and the results are listed in Table 1.

As can be seen in Table 1, the application of the optimized reaction conditions to a range of different benzylic, primary and secondary alcohols gave the corresponding esters in good to excellent yields. Benzyl alcohols bearing electron donating groups, such as $p$-methoxybenzyl alcohol, reacted faster than benzyl alcohol (Table 1, entry 2), whereas benzyl alcohols bearing electron withdrawing groups, such $o$-nitrobenzyl alcohol, reacted sluggishly with the corresponding ester being isolated in $88 \%$ yield after $5.5 \mathrm{~h}$ (Table 1, entry 5). Primary and secondary alcohols generally provided high yields of the desired products under the optimized conditions, whereas the tertiary alcohol 1-adamantanol failed to provide any of the desired product (Table 1, entry 11). It is noteworthy that the optically active alcohol, (-)-menthol, gave menthyl acetate in $75 \%$ isolated yield (Table 1, entry 10). Based on a comparison of the optical rotation of the menthyl acetate product with the value from the literature [25], the reaction was found to occur with a high level of retention and optical purity ( $97 \%$ ee). The application of the optimized conditions to enolizable 1,3diketones that could not form cyclic hydrogen-bonded structures gave the corresponding enol-acetates. For example, 5,5dimethyl-1,3-cyclohexanedione was quantitatively converted to the corresponding enol-acetate (Table 1, entry 25). In contrast, pentane-2,4-dione, which is an enolizable 1,3-diketone capable of forming a cyclic hydrogen-bonded structure, did not react at all under the optimized conditions and was recovered quantitatively after $24 \mathrm{~h}$ (Table 1, entry 26).

Following the successful conversion of alcohols into the corresponding alkyl acetates, we also investigated the applica- 
Table 1

Acetylation of alcohols, phenols, and amines with acetic anhydride in the presence of acylimidazolium acetate at ambient temperature.

\begin{tabular}{|c|c|c|c|c|}
\hline Entry & Substrate & Product & $\begin{array}{c}\text { Time } \\
\text { (h) }\end{array}$ & $\begin{array}{l}\text { Isolated } \\
\text { yield (\%) }\end{array}$ \\
\hline 1 & $\mathrm{C}_{6} \mathrm{H}_{5} \mathrm{CH}_{2} \mathrm{OH}$ & $\mathrm{C}_{6} \mathrm{H}_{5} \mathrm{CH}_{2} \mathrm{OAc}$ & 3 & 94 \\
\hline 2 & $4-\mathrm{CH}_{3} \mathrm{OC}_{6} \mathrm{H}_{4} \mathrm{CH}_{2} \mathrm{OH}$ & 4- $\mathrm{CH}_{3} \mathrm{OC}_{6} \mathrm{H}_{4} \mathrm{CH}_{2} \mathrm{OAc}$ & 2.5 & 86 \\
\hline 3 & $4-\mathrm{ClC}_{6} \mathrm{H}_{4} \mathrm{CH}_{2} \mathrm{OH}$ & 4- $\mathrm{ClC}_{6} \mathrm{H}_{4} \mathrm{CH}_{2} \mathrm{OAc}$ & 2.6 & 90 \\
\hline 4 & $4-\mathrm{BrC}_{6} \mathrm{H}_{4} \mathrm{CH}_{2} \mathrm{OH}$ & 4- $\mathrm{BrC}_{6} \mathrm{H}_{4} \mathrm{CH}_{2} \mathrm{OAc}$ & 2.6 & 88 \\
\hline 5 & $2-\mathrm{O}_{2} \mathrm{NC}_{6} \mathrm{H}_{4} \mathrm{CH}_{2} \mathrm{OH}$ & $2-\mathrm{O}_{2} \mathrm{NC}_{6} \mathrm{H}_{4} \mathrm{CH}_{2} \mathrm{OAc}$ & 5.5 & 88 \\
\hline 6 & $\mathrm{C}_{6} \mathrm{H}_{5} \mathrm{CH}_{2} \mathrm{CH}_{2} \mathrm{OH}$ & $\mathrm{C}_{6} \mathrm{H}_{5} \mathrm{CH}_{2} \mathrm{CH}_{2} \mathrm{OAc}$ & 4.5 & 81 \\
\hline 7 & $\mathrm{C}_{6} \mathrm{H}_{5} \mathrm{CH}(\mathrm{OH}) \mathrm{CH}_{3}$ & $\mathrm{C}_{6} \mathrm{H}_{5} \mathrm{CH}(\mathrm{OAc}) \mathrm{CH}_{3}$ & 14 & 83 \\
\hline 8 & $\mathrm{CH}_{3}\left(\mathrm{CH}_{2}\right)_{6} \mathrm{CH}_{2} \mathrm{OH}$ & $\mathrm{CH}_{3}\left(\mathrm{CH}_{2}\right)_{6} \mathrm{CH}_{2} \mathrm{OAc}$ & 8 & 91 \\
\hline 9 & $\mathrm{CH}_{3}\left(\mathrm{CH}_{2}\right)_{5} \mathrm{CH}(\mathrm{OH}) \mathrm{CH}_{3}$ & $\mathrm{CH}_{3}\left(\mathrm{CH}_{2}\right)_{5} \mathrm{CH}(\mathrm{OAc}) \mathrm{CH}_{3}$ & 24 & 77 \\
\hline 10 & $(-)$-Menthol & (-)-Menthyl acetate & 24 & 75 \\
\hline 11 & 1-Adamantanol & - & 24 & - \\
\hline 12 & $\mathrm{C}_{6} \mathrm{H}_{5} \mathrm{OH}$ & $\mathrm{C}_{6} \mathrm{H}_{5} \mathrm{OAc}$ & 2.5 & 95 \\
\hline 13 & 4- $\mathrm{CH}_{3} \mathrm{OC}_{6} \mathrm{H}_{4} \mathrm{OH}$ & 4- $\mathrm{CH}_{3} \mathrm{OC}_{6} \mathrm{H}_{4} \mathrm{OAc}$ & 0.75 & 92 \\
\hline 14 & 4- $\mathrm{BrC}_{6} \mathrm{H}_{4} \mathrm{OH}$ & 4- $\mathrm{BrC}_{6} \mathrm{H}_{4} \mathrm{OAc}$ & 0.5 & 92 \\
\hline 15 & $4-\mathrm{C}_{2} \mathrm{H}_{5} \mathrm{C}_{6} \mathrm{H}_{4} \mathrm{OH}$ & 4- $\mathrm{C}_{2} \mathrm{H}_{5} \mathrm{C}_{6} \mathrm{H}_{4} \mathrm{OAc}$ & 2.5 & 87 \\
\hline 16 & $2-\mathrm{O}_{2} \mathrm{NC}_{6} \mathrm{H}_{4} \mathrm{OH}$ & $2-\mathrm{O}_{2} \mathrm{NC}_{6} \mathrm{H}_{4} \mathrm{OAc}$ & 5.5 & 89 \\
\hline 17 & $\mathrm{C}_{6} \mathrm{H}_{5} \mathrm{NH}_{2}$ & $\mathrm{C}_{6} \mathrm{H}_{5} \mathrm{NHAc}$ & $0^{\mathrm{a}}$ & 95 \\
\hline 18 & 4- $\mathrm{CH}_{3} \mathrm{OC}_{6} \mathrm{H}_{4} \mathrm{NH}_{2}$ & 4- $\mathrm{CH}_{3} \mathrm{OC}_{6} \mathrm{H}_{4} \mathrm{NHAC}$ & $0^{a}$ & 95 \\
\hline 19 & $4-\mathrm{BrC}_{6} \mathrm{H}_{4} \mathrm{NH}_{2}$ & 4- $\mathrm{BrC}_{6} \mathrm{H}_{4} \mathrm{NHAc}$ & $0^{\mathrm{a}}$ & 92 \\
\hline 20 & $4-\mathrm{CH}_{3} \mathrm{C}_{6} \mathrm{H}_{4} \mathrm{NH}_{2}$ & 4- $\mathrm{CH}_{3} \mathrm{C}_{6} \mathrm{H}_{4} \mathrm{NHAc}$ & $0^{\mathrm{a}}$ & 89 \\
\hline 21 & $4-\mathrm{O}_{2} \mathrm{NC}_{6} \mathrm{H}_{4} \mathrm{NH}_{2}$ & $4-\mathrm{O}_{2} \mathrm{NC}_{6} \mathrm{H}_{4} \mathrm{NHAc}$ & $0^{\mathrm{a}}$ & 90 \\
\hline 22 & $\mathrm{C}_{6} \mathrm{H}_{5} \mathrm{NHCH}_{3}$ & $\mathrm{C}_{6} \mathrm{H}_{5} \mathrm{~N}(\mathrm{Ac}) \mathrm{CH}_{3}$ & $0^{\mathrm{a}}$ & 89 \\
\hline 23 & $\mathrm{C}_{6} \mathrm{H}_{5} \mathrm{CH}_{2} \mathrm{NH}_{2}$ & - & 24 & - \\
\hline 24 & $\left(\mathrm{C}_{6} \mathrm{H}_{5} \mathrm{CH}_{2}\right)_{2} \mathrm{NH}$ & - & 24 & - \\
\hline 25 & & & 24 & 79 \\
\hline 26 & 只员 & - & 24 & - \\
\hline
\end{tabular}

Reaction conditions: acylimidazolium acetate $0.08 \mathrm{mmol}$, alcohol 1.0 mmol, acetic anhydride $2.0 \mathrm{mmol}$, r.t.

a These reactions occurred immediately.

bility of this reaction for the acylation of phenols using the optimized conditions. As shown in Table 1 (entries 12-16), a variety of the different phenols bearing different substituents were successfully converted to the corresponding acetates in excellent yields.

To further evaluate the scope of the current method, we also investigated the application of the optimized conditions to the acylation of amines at ambient temperature. Pleasingly, aromatic amines containing electron donating or electron withdrawing groups were successfully acetylated within $1 \mathrm{~min}$. We also examined the acetylation of primary and secondary aliphatic amines (Table 1, entries 23 and 24). Unfortunately, our attempts to acetylate these amines were unsuccessful. The failure of the optimized conditions in these cases can be explained in terms of the $\mathrm{p} K_{\mathrm{a}}$ value of the amines. For the reaction to proceed successfully, the amine needs to be able to attack the carbonyl carbon atom of $\mathrm{N}$-acylimidazolium acetate (I). If the aliphatic amine is protonated during this step, it will not be able to perform as a nucleophile.

The reusability of a catalyst is of great importance from an economical and environmental perspective. The reusability of

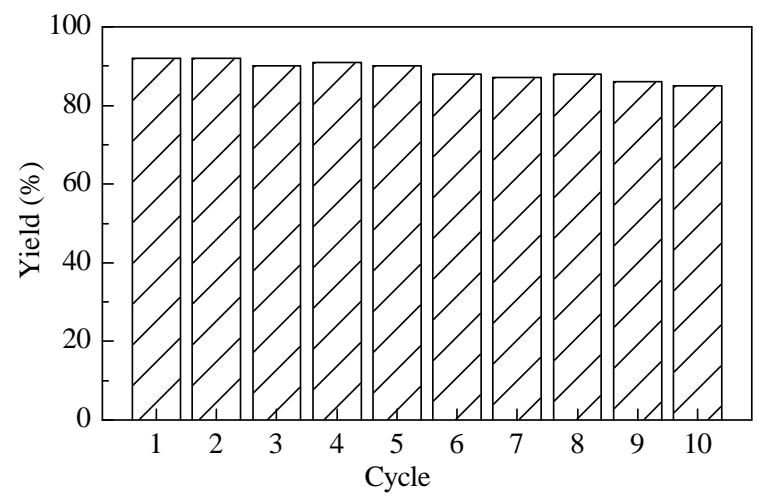

Fig. 1. Recyclability of the acylimidazolium acetate for the acetylation of 4-bromophenol with acetic anhydride. Reaction conditions: acylimidazolium acetate $0.08 \mathrm{mmol}$, 4-bromophenol $1.0 \mathrm{mmol}$, acetic anhydride $2.0 \mathrm{mmol}$, r.t.

the current catalyst was evaluated for the acetylation of 4-bromophenol with acetic anhydride. At the end of each reaction, the product was extracted with $n$-hexane, whereas the catalyst was extracted in water (ILs are soluble in water). The aqueous extract was then evaporated to dryness in vacuo to give the catalyst. The catalyst was then recycled and reused in this way 10 times. The results revealed that catalyst still afforded the corresponding acetate without any significant reduction in the yield, even after 10 cycles (Fig. 1).

Based on the results from the acylation of $(-)$-menthol, we have proposed the following reaction mechanism, which would occur with a retention in the configuration (Scheme 2).

In addition to stereochemistry, the determination of the $\mathrm{pH}$ of reaction medium could also allow for the proposed mechanism to be confirmed. With this in mind, the $\mathrm{pH}$ of the reaction mixture was determined upon completion of the acetylation reaction. The reaction medium was found to be acidic in all of the reactions studied, which is consistent with the generation of acetic acid in the reaction mixture, as shown in Scheme 2.

\section{Conclusions}

An efficient protocol for the acetylation of alcohols, phenols, and amines was found. $\mathrm{N}$-acylimidazolium acetate is introduced as an easily prepared and cheap ionic liquid that performs a catalytic activity, and can be re-used at least 10 times with no obvious loss of activity. The advantages of our system are mild reaction conditions, simplicity and ease of workup, the

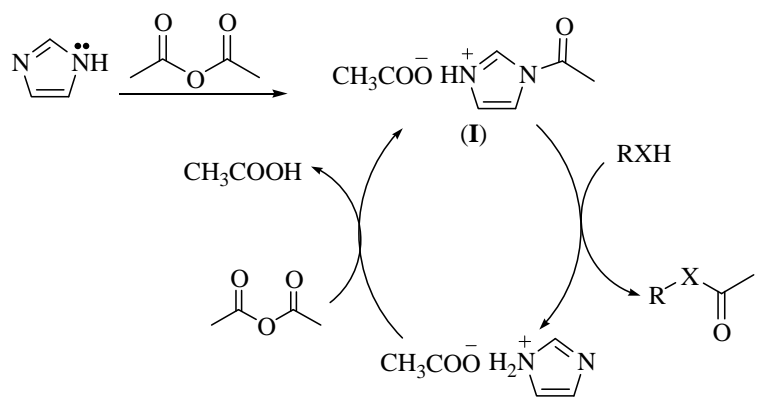

Scheme 2. The proposed mechanism for acetylation of alcohols, phenols, and amines. 


\section{Graphical Abstract}

Chin. J. Catal., 2013, 34: 1787-1790 doi: 10.1016/S1872-2067(12)60660-3

In situ generated acylimidazolium acetate as an efficient catalyst and acylating agent for the acetylation of alcohols, phenols, and amines at ambient temperature

Najmeh Nowrouzi*, Seyedeh Zahra Alizadeh

Persian Gulf University, Iran

$\mathrm{N}$-acylimidazolium acetate was successfully used as a readily preparable and inexpensive recyclable catalyst for the efficient acetylation of alcohols, phenols, and amines at ambient temperature.

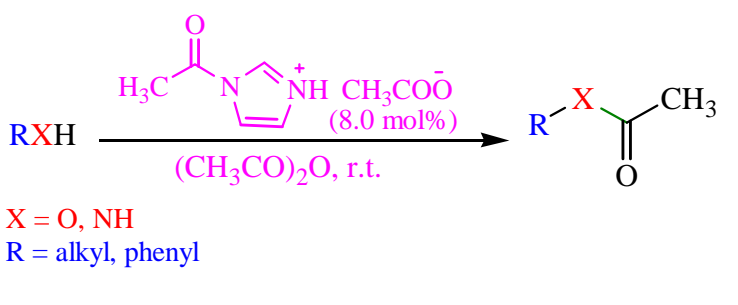

cheapness, availability and low toxicity of the reagents in contrast to the some hazardous reagents reported in the literature.

\section{References}

[1] Greene T W, Wuts P G M. Protective Group in Organic Synthesis. 3rd ed. New York: Wiley, 1999

[2] Hanson J R. Protecting Groups in Organic Synthesis: Postgraduate Chemistry Series. Blackwell Science, Inc., Malden, MA, 1999

[3] Wuts P G M, Greene T W. Greene's Protective Groups in Organic Synthesis. 4th ed. John Wiley \& Sons Inc., Hoboken, New Jersey, 2007. 222

[4] Dalpozzo R, De Nino A, Maiuolo L, Procopio A, Nardi M, Bartoli G, Romeo R. Tetrahedron Lett, 2003, 44: 5621

[5] Alleti R, Oh W S, Perambuduru M, Afrasiabi Z, Sinn E, Reddy V P. Green Chem, 2005, 7: 203

[6] Ghosh R, Maiti S, Chakraborti A. Tetrahedron Lett, 2005, 46: 147

[7] Firouzabadi H, Iranpoor N, Nowrouzi F, Amani K. Chem Commun, 2003: 764

[8] Niknam K, Saberi D. Appl Catal A, 2009, 366: 220

[9] Hajjami M, Ghorbani-Choghamarani A, Norouzi M. Chin J Catal (催 化学报), 2012, 33: 1661

[10] Ghorbani-Choghamarani A, Pourbahar N. Chin J Catal (催化学报),
2012, 33: 1470

[11] Pushpaletha P, Lalithambika M. Appl Clay Sci, 2011, 51: 424

[12] Shirini F, Imanzadeh G H, Mousazadeh S A R, MohammadpoorBaltork I, Abedin M. Chin Chem Lett, 2010, 21: 1187

[13] Yoon H J, Lee S M, Kim J H, Cho H J, Choi J W, Lee S H, Lee Y S. Tetrahedron Lett, 2008, 49: 3165

[14] Farhadi S, Panahandehjoo S. Appl Catal A, 2010, 382: 293

[15] Hofle G, Steglich W, Vorbruggen H. Angew Chem Int Ed, 1978, 17: 569

[16] Scriven E F V. Chem Soc Rev, 1983, 12: 129

[17] Sano T, Ohashi K, Oriyama T. Synthesis, 1999: 1141

[18] Steglich W, Hofle G. Angew Chem Int Ed Eng, 1969, 8: 981

[19] Vedejs E, Diver S T. J Am Chem Soc, 1993, 115: 3358

[20] Vedejs E, Bennett N S, Conn L M, Diver S T, Gingras M, Lin S, Oliver P A, Peterson M J. J Org Chem, 1993, 58: 7286

[21] López I, Luis Bravo J, Caraballo M, Luis Barneto J, Silvero G. Tetrahedron Lett, 2011, 52: 3339

[22] Hajipour A R, Khazdooz L, Ruoho A E. J Chin Chem Soc, 2009, 56: 398

[23] Wang W J, Cheng W P, Shao L L, Yang J G. Catal Lett, 2008, 121: 77

[24] Abbott A P, Bell T J, Handa S, Stoddart B. Green Chem, 2005, 7: 705

[25] Iranpoor N, Firouzabadi H, Jamalian A. Tetrahedron Lett, 2005, 46: 7963 